\title{
Acute vascular complications of femoral veno-arterial ECMO: a single-centre retrospective study
}

\author{
Mohamed Laimoud ${ }^{1,2^{*}}$, Elias Saad ${ }^{1}$ and Samer Koussayer ${ }^{3,4}$
}

\begin{abstract}
Background: Femoral arterial cannulation to initiate veno-arterial ECMO may result in ipsilateral limb ischemia due to reduced distal blood flow below the insertion point of the cannula. We retrospectively studied adult patients supported with femoral VA-ECMO for cardiogenic shock between 2015 and 2019 at our tertiary care hospital.

Results: The study included 65 adult patients supported with femoral VA-ECMO for refractory cardiogenic shock. The studied patients had a mean age of $37.9 \pm 14.87$ years, mostly males (70.8\%), a mean BSA of $1.77 \pm 0.27 \mathrm{~m}^{2}$, and a mean BMl of $26.1 \pm 6.7 \mathrm{~kg} / \mathrm{m}^{2}$. Twenty-one (32.3\%) patients developed acute lower limb ischemia. The patients who developed acute limb ischemia had significantly frequent AKI $(<0.001)$ without significant use of haemodialysis $(p=0.07)$ and longer ICU stay $(p=0.028)$ compared to the patients without limb ischemia. The hospital mortality occurred in 29 (44.6\%) patients without significant difference between the patients with and without acute limb ischemia. The occurrence of acute limb ischemia was significantly correlated with failed percutaneous cannulation ( $p=0.039$ ), while there was no significant statistical correlation between the cut-down technique and occurrence of limb ischemia $(p=0.053)$. The occurrence of femoral cannulation site bleeding was significantly correlated with failed percutaneous cannulation $(p=0.001)$ and cut-down technique $(p=0.001)$.
\end{abstract}

Conclusion: Acute vascular complications are frequent after femoral VA-ECMO. Failed percutaneous femoral cannulation has been, in this study, identified as the most important risk factor for acute limb ischemia and cannulation site bleeding. A careful approach during femoral cannulation is recommended to prevent occurrence of acute limb ischemia and femoral cannulation site bleeding.

Keywords: Veno-arterial ECMO, Femoral, Limb ischemia, Percutaneous cannulation, Ultrasound, Cut-down

\section{Background}

Emergent veno-arterial extracorporeal membrane oxygenation (VA-ECMO) is increasingly used to provide rapid cardiopulmonary resuscitation in adult patients with refractory cardiogenic shock [1-3]. The emergent nature of the haemodynamics deterioration, as in cardiac arrest or post-cardiotomy shock conditions, makes

\footnotetext{
*Correspondence: mlaimoud@kfshrc.edu.sa; m.laimoud@cu.edu.eg; m.laimoud@hotmail.com

${ }^{1}$ Adult Cardiac Surgical Intensive Care Department, King Faisal Specialist Hospital \& Research Center, Riyadh, Saudi Arabia

${ }^{2}$ Critical Care Medicine Department, Cairo University, Cairo, Egypt

Full list of author information is available at the end of the article
}

peripheral ECMO initiation via femoral vessels the preferred approach. Either percutaneous or surgical cutdown approaches are being used for emergent femoral cannulation to initiate VA-ECMO support $[4,5]$. Femoral arterial cannulation may result in ipsilateral limb ischemia due to reduced distal blood flow below the insertion point of the cannula [6-8]. Recent studies have demonstrated that the development of acute limb ischemia had a bad impact on patient mortality and quality of life of the survivors after ECMO decannulation $[9,10]$. We conducted this retrospective study to report and analyse the vascular complications of peripheral VA- 
ECMO in the adult patients with cardiogenic shock in our tertiary care hospital.

\section{Methods \\ The study design}

The ethics committee board of our institute approved this retrospective study. We included adult patients who were supported with femoral veno-arterial ECMO for cardiogenic shock between 2015 and 2019 at our tertiary care hospital. The enrolled patients were divided according to occurrence of acute lower limb ischemia into 2 groups. The hospital electronic database was used to get the clinical and laboratory variables of studied patients. We assessed the studied patients using SOFA score upon ICU admission and then at the third and fifth days. The $\Delta 1$ SOFA was the difference between SOFA scores at third and admission days. The $\triangle 2$ SOFA was the difference between SOFA scores at the fifth and admission days [11-13].

\section{The femoral cannulation technique}

The femoral arterial and venous cannulations were done via either percutaneous or cut-down approaches according to the surgeons preferences. Seldinger technique was use to cannulate the femoral vein and a 19-23-Fr cannula was introduced over a guidewire till the inferior vena cava (IVC). The common femoral artery was similarly cannulated with a 15-19-Fr cannula. Insertion of an additional distal 6-Fr cannula was also performed to preserve lower limb perfusion in most of enrolled patients. The selection of type and size of the arterial cannula was selected according to the patient's body surface area (BSA) and the required ECMO flow which is equivalent to a cardiac index (CI) of $2.2-2.5 \mathrm{~L} / \mathrm{m}^{2} / \mathrm{min}[14]$.

\section{The ECMO management and decannulation protocol}

After VA-ECMO initiation, the blood flow was adjusted based on clinical evaluation including mean arterial blood pressure, urine output, clearance of blood hyperlactatemia, and mixed venous oxygen saturation. Titration of oxygen and sweep flows was gradually done to achieve acceptable blood gases. Minimization of the doses of vasopressors intravenous infusions was done to decrease risk of limb ischemia. Anticoagulation was done via intravenous heparin infusion which was adjusted according to heparin assay (target 0.3-0.7 units/ $\mathrm{ml}$ ), antithrombin (AT) III (goal 80-120\%), and clinical tolerance. Platelets transfusion to keep count more than $50\left(10^{9} / \mathrm{L}\right)$, packed red blood corpuscles transfusion to maintain the haemoglobin level above $80(\mathrm{gm} / \mathrm{L})$ were done. Monitoring of the lower limbs perfusion was routinely done by clinical and Doppler ultrasound assessments. The clinical assessment includes skin temperature and appearance to detect any coldness, pallor or mottling compared to contralateral limb, and cannulation site bleeding or haematoma. Doppler ultrasound assessment was used to detect the peak systolic velocity of dorsalis pedis and posterior tibial arteries. Near-infrared spectroscopy (NIRS) monitoring is routinely applied to all patients with femoral VA-ECMO to provide continuous monitoring cerebral oxygenation via bilateral frontal probes. Also, NIRS was used in patients with suspected limb impaired perfusion via limb probes. NIRS was proved to be effective in continuous monitoring of limb regional oxygen saturation even with absence of pulsatile flow $[15,16]$. For any suspicion of limb ischemia, complete involvement of vascular surgery team was done. Removal of femoral cannulae was done after exposing the femoral vessels. The femoral vessels were primarily repaired. In case of limb ischemia, vascular surgical interventions were done including thrombectomy and angioplasty. Fasciotomy was done in case of acute leg compartmental syndrome.

\section{The statistical analysis}

Data was coded and entered using the Statistical Package for the Social Sciences (SPSS) version 26 (IBM Corp., Armonk, NY, USA). Data was presented using mean ( \pm standard deviation) or median (interquartile range) in quantitative data and using frequency (and percentage) for categorical data. Comparisons between quantitative variables were done using the Mann-Whitney test. For comparing categorical data, Chi square $\left(\chi^{2}\right)$ test was performed. Graphs were used to illustrate some information. $p$ values less than 0.05 were considered statistically significant.

\section{Results}

Baseline clinical variables of studied patients

The study included 65 adult patients supported with femoral VA-ECMO for refractory cardiogenic shock. The studied patients had a mean age of $37.9 \pm 14.87$ years, mostly males (70.8\%), a mean BMI of $26.1 \pm 6.7$ $\mathrm{kg} / \mathrm{m}^{2}$ and a mean BSA of $1.77 \pm 0.27 \mathrm{~m}^{2}$. Twenty-one (32.3\%) patients developed acute lower limb ischemia. There were no statistically significant differences between the patients with and without limb ischemia regarding demographic data, clinical variables, size of ECMO cannulae, prophylactic distal perfusion cannula (DPC) insertion ultrasound-guided approach, and cutdown approaches. Failed percutaneous cannulae insertion was statistically significant in the patients who developed acute limb ischemia (Table 1).

\section{The vascular complications of studied patients}

Femoral thrombectomy and angioplasty were done in 20 (30.8\%) patients. Four (6.2\%) patients developed limb 
Table 1 Baseline clinical variables of the VA-ECMO-supported patients

\begin{tabular}{|c|c|c|c|c|}
\hline Studied criteria & All patients $(n=65)$ & Limb ischemia group $(n=21)$ & No limb ischemia group $(n=44)$ & $P$ value \\
\hline Age (years) & $37.9 \pm 14.87$ & $34.4 \pm 12.3$ & $39.6 \pm 15.8$ & 0.19 \\
\hline \multicolumn{5}{|l|}{ Sex } \\
\hline Males & $46(70.8)$ & $18(85.7)$ & $28(63.6)$ & \multirow[t]{2}{*}{0.06} \\
\hline Females & $19(29.2)$ & $3(14.3)$ & $16(36.4)$ & \\
\hline Weight (kg) & $70.88 \pm 20.9$ & $70.6 \pm 23.4$ & $71 \pm 19.9$ & 0.61 \\
\hline Height $(\mathrm{cm})$ & $164.68 \pm 8.1$ & $164.57 \pm 6.3$ & $164.7 \pm 8.9$ & 0.83 \\
\hline $\mathrm{BMI}\left(\mathrm{kg} / \mathrm{m}^{2}\right)$ & $26.08 \pm 6.7$ & $26.04 \pm 7.7$ & $26.11 \pm 6.4$ & 0.43 \\
\hline $\mathrm{BSA}\left(\mathrm{m}^{2}\right)$ & $1.77 \pm 0.27$ & $1.76 \pm 0.29$ & $1.78 \pm 0.27$ & 0.54 \\
\hline Diabetes mellitus & $13(20)$ & $5(23.8)$ & $8(18.2)$ & 0.74 \\
\hline Hypertension & $18(27.7)$ & $5(23.8)$ & $13(29.5)$ & 0.62 \\
\hline Pre-ECMO AF & $17(26.2)$ & $4(19)$ & $13(29.5)$ & 0.36 \\
\hline Anticoagulants intake & $18(27.7)$ & $5(23.8)$ & $13(29.5)$ & 0.62 \\
\hline Aspirin intake & $3(4.6)$ & $1(4.8)$ & $2(4.5)$ & 1 \\
\hline Left ventricle EF & $26.75 \pm 13.4$ & $26.14 \pm 12.1$ & $27.1 \pm 14.2$ & 0.81 \\
\hline CKD & $10(15.4)$ & $5(23.8)$ & $5(11.4)$ & 0.27 \\
\hline Previous CVS & $2(3.1)$ & $1(4.8)$ & $1(2.3)$ & 0.54 \\
\hline Cardiothoracic surgery & $17(26.2)$ & $6(28.6)$ & $11(25)$ & 0.75 \\
\hline IABP & $13(20)$ & $4(19)$ & $9(20.5)$ & 1 \\
\hline \multicolumn{5}{|l|}{ Percutaneous cannula insertion } \\
\hline Successful & $36(55.4)$ & $8(38.1)$ & $28(63.6)$ & \multirow[t]{3}{*}{0.039} \\
\hline Failed & $19(29.2)$ & $10(47.6)$ & $9(20.5)$ & \\
\hline Not tried & $10(15.4)$ & $3(14.3)$ & $7(15.9)$ & \\
\hline US-guided cannula insertion & $32(49.2)$ & $7(33.3)$ & $25(56.8)$ & 0.07 \\
\hline Femoral cut-down & $29(44.6)$ & $13(61.9)$ & $16(36.4)$ & 0.053 \\
\hline Insertion at operation room & $30(46.2)$ & $13(61.9)$ & $17(38.6)$ & 0.078 \\
\hline Arterial cannula size (Fr) & $17.85 \pm 1.4$ & $18.05 \pm 1.36$ & $17.75 \pm 1.43$ & 0.77 \\
\hline Venous cannula size ( $F r)$ & $21.72 \pm 1.3$ & $21.6 \pm 1.59$ & $21.7 \pm 1.22$ & 0.82 \\
\hline Distal perfusion cannula & $52(80)$ & $15(71.4)$ & $37(84.1)$ & 0.32 \\
\hline Cannulation site bleeding & $16(24.6)$ & $6(28.6)$ & $10(22.7)$ & 0.6 \\
\hline Cannulation bleeding required exploration & $4(6.3)$ & $1(4.8)$ & $3(6.8)$ & 1 \\
\hline
\end{tabular}

Data are presented as number (\%) or mean $( \pm$ SD)

compartmental syndrome and fasciotomy was done. Amputation of toes was done in one patient. The vascular complications included femoral arteriovenous fistula after ECMO decannulation and required vascular surgical repair in one patient. Femoral large pseudoaneurysm occurred in one patient and required surgical intervention after ECMO decannulation. Three (4.6\%) patients developed chronic limb ischemia manifestations during follow-up. Femoral wound infection occurred in $2(3.1 \%)$ patients and complicated the healing process and required sartolius muscle flapping (Table 2, Fig. 1).

\section{Laboratory criteria of studied VA-ECMO-treated patients}

The patients who develop limb ischemia had significantly higher INR $(1.9(1.4-3.2)$ vs $1.4(1.1-3.6), p=$ $0.004)$ and AT III level (69 (27-88) vs 55.5 (42-73), $p=$ 0.002 ) at time of ECMO initiation compared to those
Table 2 The vascular complications of the studied patients

\begin{tabular}{ll}
\hline The vascular complications & Number (\%) \\
\hline Acute limb ischemia & $21(32.3)$ \\
Thrombectomy & $20(30.8)$ \\
Angioplasty & $20(30.8)$ \\
Fasciotomy & $4(6.2)$ \\
Toes amputation & $1(1.5)$ \\
Cannulation site bleeding & $16(24.6)$ \\
Cannulation bleeding required exploration & $4(6.3)$ \\
Femoral arteriovenous fistula & $1(1.5)$ \\
Femoral pseudo-aneurysm & $1(1.5)$ \\
Ipsilateral chronic limb ischemia & $3(4.6)$ \\
Groin wound grafting & $2(3.1)$ \\
\hline
\end{tabular}




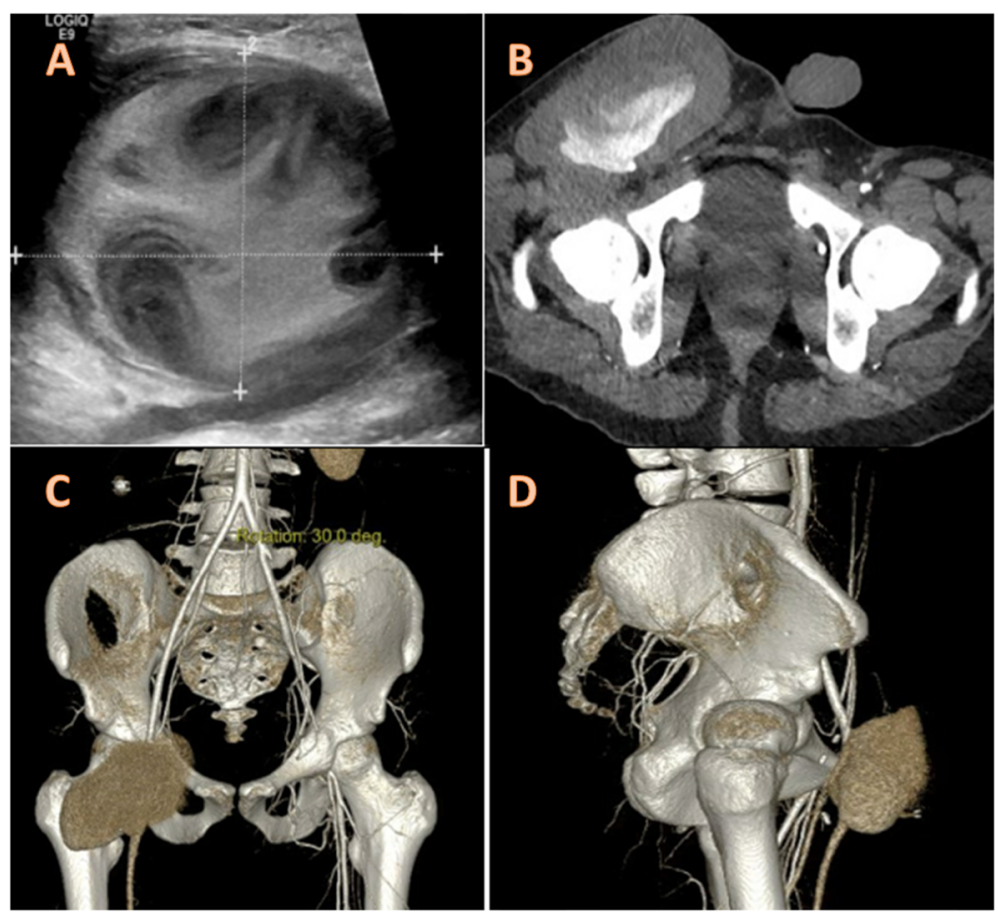

Fig. 1 A 21-year-old male patient developed acute right groin swelling after right femoral ECMO decannulation. Groin US revealed a large swelling $(7 \times 5 \mathrm{~cm})$ with heterogenous echogenicity in the right groin area arising from right femoral artery with the neck measuring $0.6 \mathrm{~cm}(\mathbf{a})$. CT angiography revealed the large pseudo-aneurysm $(12 \times 6 \mathrm{~cm})$ from the right common femoral artery with active contrast extravasation (b). Multiplanar reconstruction and advanced 3-D postprocessing were performed and revealed the large pseudo-aneurysm with good distal arterial flow $(\mathbf{c}, \mathbf{d})$. Vascular surgery was done with evacuation of the pseudo-aneurysm and repair of the femoral artery

Table 3 Laboratory criteria of the studied VA-ECMO-treated patients

\begin{tabular}{|c|c|c|c|c|}
\hline Studied criteria & All patients & Limb ischemia group & No limb ischemia group & $P$ value \\
\hline Haemoglobin (g/L) & $111(88-166)$ & 105 (88-153) & $111(88-166)$ & 0.9 \\
\hline Platelet count $\left(10^{9} / \mathrm{L}\right)$ & $181(38-447)$ & $160(112-329)$ & $215(38-447)$ & 0.32 \\
\hline INR & $1.6(1.1-3.6)$ & $1.9(1.4-3.2)$ & $1.4(1.1-3.6)$ & 0.004 \\
\hline aPTT (seconds) & $42.2(31.3-150)$ & $48.2(33.9-150)$ & $41.3(31.3-74.3)$ & 0.06 \\
\hline PTT ratio & $1.2(0.9-4.4)$ & $1.4(1-4.4)$ & $1.2(0.9-2.2)$ & 0.13 \\
\hline Fibrinogen ( $g / L)$ & $3.16(0.76-6.87)$ & $2.38(0.76-6.87)$ & $3.39(1.37-6.06)$ & 0.28 \\
\hline Antithrombin III & $58(27-88)$ & $69(27-88)$ & $55.5(42-73)$ & 0.002 \\
\hline Serum creatinine $(\mu \mathrm{mol} / \mathrm{L})$ & $91(9.5-320)$ & 115 (48-298) & $81(9.5-320)$ & 0.01 \\
\hline Serum albumin (g/L) & $32.2(18.3-44.1)$ & $37.4(22.2-44.1)$ & $31.1(18.3-44.1)$ & 0.04 \\
\hline Serum bilirubin ( $\mu \mathrm{mol} / \mathrm{L})$ & $28.6(5.8-389)$ & $58.7(5.8-79.7)$ & $53.5(7.5-389)$ & 0.71 \\
\hline $\mathrm{PH}$ & $7.17(6.9-7.34)$ & $7.12(6.9-7.34)$ & $7.20(6.9-7.34)$ & 0.69 \\
\hline Base excess & $-9.3(-18.6$ to -4.8$)$ & $-11.2(-18.6$ to -5.3$)$ & $-8.25(-16.4$ to -4.8$)$ & 0.25 \\
\hline Blood lactate $(\mathrm{mmol} / \mathrm{L})$ & $4.8(2.4-12.4)$ & $4.8(3.6-12.4)$ & $5.2(2.4-10.7)$ & 0.91 \\
\hline Peak blood lactate & $13.2(6.7-20)$ & $13.2(7.4-20)$ & $11.2(6.7-20)$ & 0.08 \\
\hline Blood lactate at $24 \mathrm{~h}$ & $3.1(1.1-20)$ & $3.1(1.1-14.3)$ & $2.9(1.1-20)$ & 0.27 \\
\hline
\end{tabular}

Data are presented as median (IQR) 
who did not develop ischemia. The serum creatinine was $115(48-298)$ vs $81(9.5-320)(p=0.01)$, while the serum albumin was $37.4(22.2-44.1)$ vs $31.1(18.3-44.1)(p=$ 0.04) in the limb ischemia and no limb ischemia groups, respectively. There were no significant differences between both groups regarding other laboratory variables including degree of lactic acidosis and lactate clearance after $24 \mathrm{~h}$ of ECMO support (Table 3).

\section{Hospital course of studied VA-ECMO-treated patients}

The hospital mortality occurred in 29 (44.6\%) patients without significant difference between both groups. The patients who developed acute limb ischemia had significantly frequent acute kidney injury (AKI) $(<0.001)$ without significant use of haemodialysis $(p=0.07)$ and longer ICU stay $(p=0.028)$ compared to the patients without limb ischemia. The median initial SOFA score was $10(8-21)$ vs $14(8-21)(p=0.008)$ in the limb ischemia and no limb ischemia groups, respectively, without significant differences in the follow-up $\triangle$ SOFA scores at the third and fifth days. There were no significant differences between both groups regarding cerebrovascular strokes, gastrointestinal bleeding, occurrence of new AF, ECMO, and ventilator days (Table 4).
The occurrence of acute limb ischemia was significantly correlated with failed percutaneous femoral cannulation $(p=0.039)$ as failed insertion occurred in $47.6 \%$ vs $20.5 \%$, while successful insertion occurred in $38.1 \%$ vs $63.6 \%$ in the patients with and without limb ischemia, respectively. There was no significant statistical correlation between the cut-down technique and occurrence of limb ischemia ( $p=0.053)$. The occurrence of femoral cannulation site bleeding was significantly correlated with failed percutaneous cannulation $(p=0.001)$ and cut-down technique $(p=0.001)$. Failed percutaneous insertion occurred in $62.5 \%$ vs $18.4 \%$, while the cut-down technique was done in $81.3 \%$ vs $32.7 \%$ of the patients with and without cannulation site bleeding, respectively (Tables 1 and 5, Figs. 2 and 3).

\section{Discussion}

We retrospectively analysed our adult patients who had femoral VA-ECMO support for refractory cardiogenic shock including post-cardiotomy shock in $26.2 \%$ of patients. We observed acute lower limb ischemia in 32.3\% of cases and cannulation site bleeding in $24.6 \%$ of cases while bleeding required vascular exploration happened in $6.3 \%$ of cases. We reviewed the recent literature about

Table 4 Hospital course of the studied VA-ECMO-treated patients

\begin{tabular}{|c|c|c|c|c|}
\hline Studied criteria & All patients & Limb ischemia group & No limb ischemia group & $P$ value \\
\hline Acute Kidney injury & $39(60)$ & $21(100)$ & $18(40.9)$ & $<0.001$ \\
\hline Renal replacement therapy & $27(41.5)$ & $12(57.1)$ & $15(34.1)$ & 0.07 \\
\hline Cerebrovascular stroke & $13(20)$ & $5(23.8)$ & $8(18.2)$ & 0.74 \\
\hline Cerebral ischemic stroke & $7(11.9)$ & $3(17.6)$ & $4(9.5)$ & 0.39 \\
\hline Intracerebral haemorrhage & $6(10.2)$ & $2(11.8)$ & $4(9.5)$ & 0.9 \\
\hline ICU days & $19(3-191)$ & $19(10-93)$ & $17(3-191)$ & 0.028 \\
\hline Ventilator days & $10(2-191)$ & $14(5-81)$ & $9(2-191)$ & 0.053 \\
\hline Gastrointestinal bleeding & $14(21.5)$ & $4(19)$ & $10(22.7)$ & 0.92 \\
\hline Atrial fibrillation & $25(38.5)$ & $9(42.9)$ & $16(36.4)$ & 0.61 \\
\hline Intracardiac thrombi & $4(6.2)$ & $1(4.8)$ & $3(6.8)$ & 0.9 \\
\hline ECMO circuits thrombi & $4(6.2)$ & $1(4.8)$ & $3(6.8)$ & 0.9 \\
\hline ECMO days before ischemia & $6(1-21)$ & $6(1-21)$ & ------ & --- \\
\hline ECMO days & $8(3-40)$ & $7(4-40)$ & $8(3-32)$ & 0.27 \\
\hline Changing to central VA-ECMO & $3(4.6)$ & $2(9.5)$ & $1(2.3)$ & 0.29 \\
\hline Changing to LVAD & $11(16.9)$ & $4(19)$ & $7(15.9)$ & 0.34 \\
\hline Decannulation and no MCS & $51(78.5)$ & $15(71.4)$ & $36(81.8)$ & 0.41 \\
\hline Hospital mortality & $29(44.6)$ & $9(42.9)$ & $20(45.5)$ & 0.84 \\
\hline SOFA score day 1 & $12(8-21)$ & $10(8-21)$ & $14(8-21)$ & 0.008 \\
\hline SOFA score day 3 & $13(6-24)$ & $10(7-22)$ & $14(6-24)$ & 0.034 \\
\hline$\triangle 1$ SOFA & $-1(-5$ to 6$)$ & $1(-4$ to 6$)$ & $-2(-5$ to 6$)$ & 0.12 \\
\hline SOFA score day 5 & $10(5-24)$ & $9(6-21)$ & $10(5-24)$ & 0.45 \\
\hline$\triangle 2$ SOFA & $-2(-7$ to 9$)$ & $0(-5$ to 8$)$ & $-3(-7$ to 9$)$ & 0.14 \\
\hline
\end{tabular}

Data are presented as number (\%) or median (IQR) 
Table 5 The correlations between cannulation site bleeding and cannulation techniques

\begin{tabular}{llll}
\hline Variables & Cannulation site bleeding & No site bleeding & $P$ value \\
\hline $\begin{array}{llll}\text { Percutaneous cannulation } \\
\text { Successful }\end{array}$ & $3(18.8 \%)$ & $33(67.3 \%)$ & 0.001 \\
Failed & $10(62.5 \%)$ & $9(18.4 \%)$ & \\
Not tried & $3(18.8 \%)$ & $7(14.3 \%)$ & \\
Cut-down & & & \\
Done & $13(81.3 \%)$ & $16(32.7 \%)$ & 0.001 \\
Not done & $3(18.8 \%)$ & $33(67.3 \%)$ & \\
\hline
\end{tabular}

the vascular complications after VA-ECMO and found a wide range of incidence which may be related to different patients' demographic data, indications and cannulation techniques of VA-ECMO and use of distal perfusion cannulae $[8,10,17-20]$.

Our incidence of acute limb ischemia was similar to Yen et al.'s study that reported acute limb ischemia in 33\% of VA-ECMO-treated patients, even with the use of DPC [8]. Our results were different from Yang et al. [18] study that reported only $8.6 \%$ incidence of acute lower limb ischemia. That difference may be related to the difference of studied patients as that study included only patients with post-cardiotomy shock and the ECMO cannulae were inserted by cutdown approach only with concomitant prophylactic DPC insertion. Tanaka et al. reported $20 \%$ incidence of acute vascular complications included a $12 \%$ incidence of acute limb ischemia with compartmental syndrome requiring fasciotomy, even in the presence of DPC [10]. Gander et al.'s study reported 52\% incidence of limb ischemia requiring surgical interventions and $81 \%$ of those patients had prophylactic DPC [21].

The development of acute limb ischemia can occur at ECMO initiation, support, or after decannulation due to multifactorial reduced blood flow to the limb especially in absence of collateral circulation. The use of relatively large-sized arterial cannulae in relation to the arterial femoral artery diameter or BSA was associated with acute limb ischemia in some studies [6,22]. Few studies reported that younger patients have higher risk of acute limb ischemia due to smaller femoral arteries and lack of collateral circulation compared to the elderly [23]. Also, female patients have higher risks compared to men due to smaller arterial sizes [10, 24]. In our study, we did not find any significant difference between both groups regarding patient age, sex, weight, height, BMI, nor BSA. Yang et al. study reported absence of age or sex differences but the patients who developed vascular complications were significantly obese [18].

Our results revealed that percutaneous approach was tried in $84.6 \%$ of patients but was successful in only $55.4 \%$ of patients. The occurrence of acute limb ischemia was significantly correlated with failed percutaneous femoral cannulation. The occurrence of femoral cannulation site bleeding was significantly correlated with failed percutaneous cannulation and cut-down technique. The percutaneous approach was the most used technique in many studies evaluating femoral VAECMO [8, 10, 25-28]. The percutaneous cannulation is characterized by being rapid easy approach with reduced risk of cannulation site bleeding but its main disadvantages include possibilities of vascular injuries and failed intraluminal catheter placement. Moreover emergent percutaneous cannulation in patients with

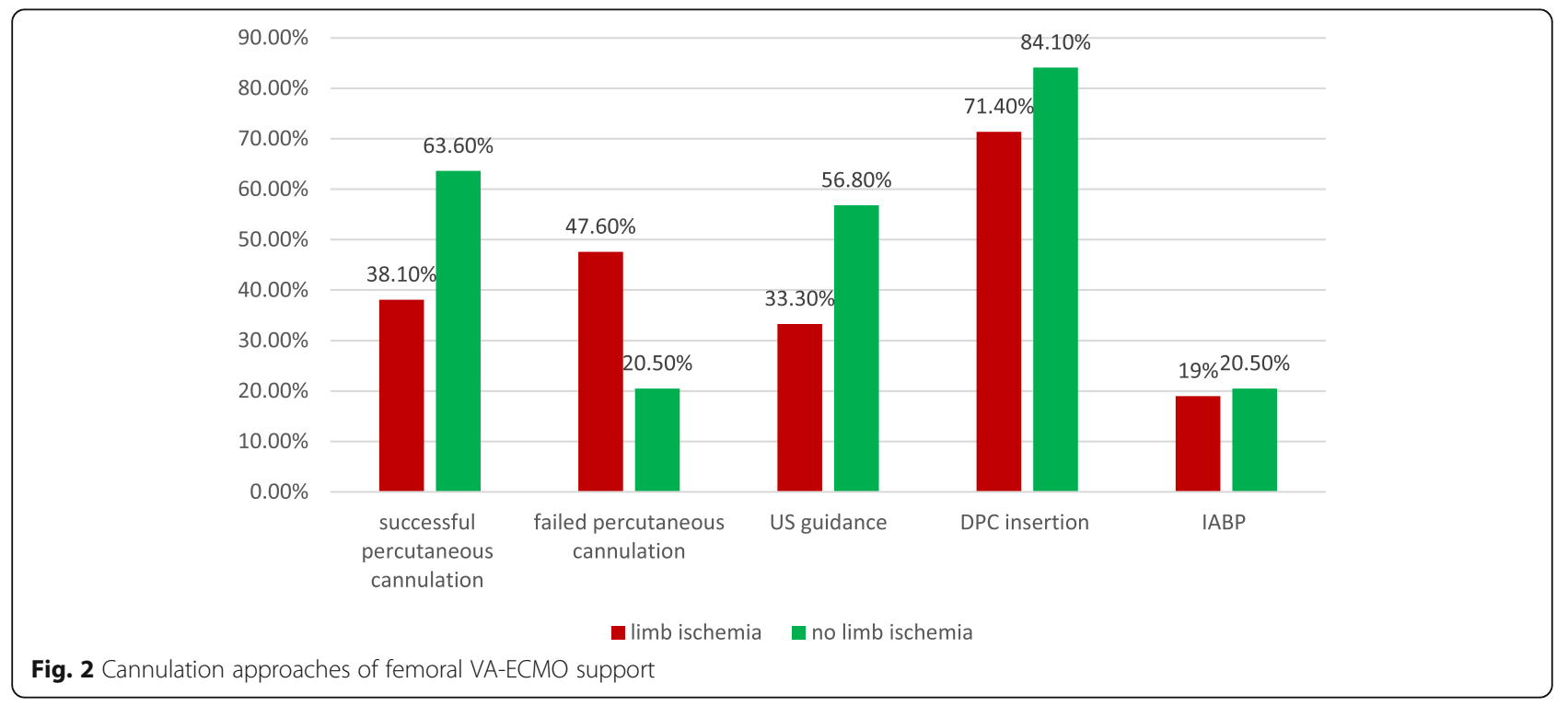




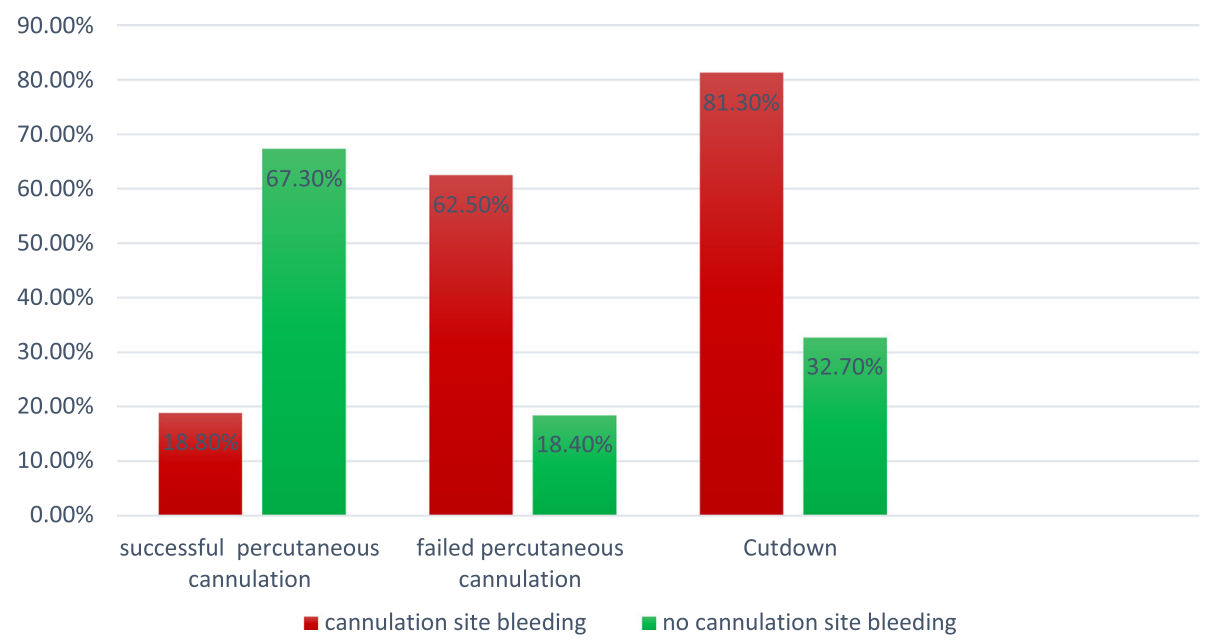

Fig. 3 Cannulation site bleeding of the studied VA-ECMO-treated patients

haemodynamics collapse is a major challenge that may be complicated with vascular complications [29, 30]. The use of ultrasound guidance in getting femoral access with first pass success was reported in many studies comparing it with the landmark techniques [31-33]. Kashiura et al. [34] recommended a combination of ultrasound guidance to get femoral access then fluoroscopy to ensure correct intraluminal guiding wire placement before dilators use and cannulae insertion. That study reported fewer vascular complications with this combination than ultrasound guidance alone without a significant delay of ECMO flow initiation.

The cut-down technique is usually done after cardiotomy with failed weaning off cardiopulmonary bypass. In our study, the cut-down technique was done mainly after failed percutaneous approach, so we could not compare between the 2 approaches regarding the vascular complications and outcomes. Slottosch et al. [35] reported the fewer vascular complications associated with the surgical approach compared with the percutaneous cannulation. However, Danial et al. [36] reported absence of significant difference between both approaches regarding acute limb ischemia in the same centre but the percutaneous approach was associated with significant bleeding requiring surgical intervention after decannulation.

Eighty percent of our studied patients had prophylactic DPC insertion with ECMO initiation and there was no significant difference between both groups. The prophylactic DPC insertion was done as a preventive strategy to avoid significant limb ischemia with variable results in many studies [8, 10, 18, 21, 37, 38]. Few trials were done to identify the patients who need a DPC instead of prophylactic insertion. Huang et al. [39] reported successful use of DPC if invasive mean arterial blood pressure was less than $50 \mathrm{mmHg}$ in femoral artery distal to the arterial cannula of ECMO. Near-infrared spectroscopy (NIRS) was used to identify the regional limb tissue oxygenation $\left(\mathrm{rSO}_{2} \%\right)$ and help to detect ischemia even with non-pulsatile blood flow. Schachner et al. [40] used NIRS monitoring and reported a drop of tissue oxygenation from 61 to $38 \%$ and going back to normal baseline values after DPC insertion. Wong et al. [41] used NIRS to concomitantly monitor brain and limb regional oxygenation. They reported clinically significant vascular events when $\mathrm{rSO}_{2} \%$ decreased below $40 \%$ or more than $25 \%$ decrease from baseline values.

According to our results and compared to patients without acute limb ischemia, the patients who developed acute ischemia had significant AKI and longer ICU stay but without significant haemodialysis, cerebral strokes, nor hospital mortality. Yang et al. [18] reported similar cerebrovascular stokes and renal replacement therapy but fewer ICU stay and fewer hospital mortality in the patients who developed acute vascular complications compared to the patients without vascular complications after peripheral VA-ECMO for post-cardiotomy shock via femoral cut-down approach. Gander et al. [21] reported absence of mortality difference between the patients with and without acute limb ischemia. Finally according to our study, we think that the emergent femoral percutaneous cannulation in patients with haemodynamics instability and coagulopathy could result in failed cannulation trials which were associated with the acute limb ischemia and cannulation site bleeding. We could recommend a careful approach and using image modalities during the whole process of femoral cannulation, guidewire introduction and cannulae insertion, and then close monitoring of limb perfusion.

\section{Conclusion}

Acute vascular complications are frequent after femoral VA-ECMO. Failed percutaneous femoral cannulation 
has been, in this study identified as the most important risk factor for acute limb ischemia and cannulation site bleeding. A careful approach during femoral cannulation is recommended to prevent occurrence of acute limb ischemia and femoral cannulation site bleeding.

\section{Limitations}

Our work was a single-centre retrospective study with a relatively limited number of patients.

\section{Abbreviations}

AKI: Acute kidney injury; AF: Atrial fibrillation; aPTT: Activated partial thromboplastin time; BSA: Body surface area; BMI: Body mass index; CKD: Chronic kidney disease; Cl: Cardiac index; CVS: Cerebrovascular stroke; DPC: Distal perfusion cannula; EF: Ejection fraction; LVAD: Left ventricle assist device; MCS: Mechanical circulatory support; NIRS: Near-infrared spectroscopy; IABP: Intra-aortic balloon pump; INR: International normalized ratio; SOFA: Sequential organ failure assessment; US: Ultrasound; VAECMO: Veno-arterial extracorporeal membrane oxygenation

\section{Acknowledgements}

We would like to thank the Cardiac Surgical Intensive Care Unit (adult CSICU) team of King Faisal Specialist Hospital for their excellent work.

\section{Authors' contributions}

All authors contributed to the research. ML has taken part in the conception and design of the study, collection, analysis and interpretation of the data, drafting of the manuscript, and final approval of the manuscript submitted. ES has taken part in the design of the study, analysis and interpretation of the data, and revision of the manuscript. SK has taken part in the design of the study, interpretation of the data, and revision of the manuscript. The authors have read and approved the final manuscript.

\section{Funding}

The authors did not receive any funding for this study.

\section{Availability of data and materials}

The data used in this study are available from the corresponding author upon a reasonable request.

\section{Ethics approval and consent to participate}

The study was approved by the Ethical Committee of King Faisal Specialist Hospital and Research Center with a reference number 2191186 and exempted from a specific consent, being a retrospective analytic study that reveals no identifiable private information.

\section{Consent for publication}

Not applicable.

\section{Competing interests}

The authors declare no competing interests.

\section{Author details}

${ }^{1}$ Adult Cardiac Surgical Intensive Care Department, King Faisal Specialist Hospital \& Research Center, Riyadh, Saudi Arabia. ${ }^{2}$ Critical Care Medicine Department, Cairo University, Cairo, Egypt. ${ }^{3}$ Vascular and Endovascular Surgery Department, King Faisal Specialist Hospital \& Research Center, Riyadh, Saudi Arabia. ${ }^{4}$ College of Medicine, Alfaisal University, Riyadh, Saudi Arabia

Received: 11 January 2021 Accepted: 8 February 2021

Published online: 19 February 2021

\section{References}

1. Abrams D, Garan AR, Abdelbary A, Bacchetta M, Bartlett RH et al (2018) Position paper for the organization of ECMO programs for cardiac failure in adults. Intensive Care Med 44(6):717-729
2. Raffa GM, Gelsomino S, Sluijpers N, Meani P, Alenizy K et al (2017) Inhospital outcome of post-cardiotomy extracorporeal life support in adult patients: the 2007-2017 Maastricht experience. Crit Care Resusc 19(Suppl 1):53-61

3. Lorusso R, Gelsomino S, Parise O, Mendiratta P, Prodhan P et al (2017) Venoarterial extracorporeal membrane oxygenation for refractory cardiogenic shock in elderly patients: trends in application and outcome from the extracorporeal life support organization (ELSO) registry. Ann Thorac Surg 104(1):62-69

4. Jayaraman A, Cormican D, Shah P, Ramakrishna H (2017) Cannulation strategies in adult veno-arterial and veno-venous extracorporeal membrane oxygenation: techniques, limitations, and special considerations. Ann Card Anaesth 20(5):11

5. Roussel A, Al-Attar N, Alkhoder S, Radu C, Raffoul R et al (2012) Outcomes of percutaneous femoral cannulation for venoarterial extracorporeal membrane oxygenation support. Eur Heart J Acute Cardiovasc Care 1:111-114

6. Banfi C, Pozzi M, Brunner M-E, Rigamonti F, Murith N et al (2016) Venoarterial extracorporeal membrane oxygenation: an overview of different cannulation techniques. J Thorac Dis 8(9):E875-E885

7. Yau P, Xia Y, Shariff S, Jakobleff WA, Forest S et al (2019) Factors associated with ipsilateral limb ischemia in patients undergoing femoral cannulation extracorporeal membrane oxygenation (ECMO). Ann Vasc Surg 54:60-65

8. Yen CC, Kao CH, Tsai CS, Tsai SH (2018) Identifying the risk factor and prevention of limb ischemia in extracorporeal membrane oxygenation with femoral artery cannulation. Heart Surg Forum 21(1):E18-E22

9. Kaushal M, Schwartz J, Gupta N, Im J, Leff J, Jakobleff WA et al (2019) Patient demographics and extracorporeal membranous oxygenation (ECMO)-related complications associated with survival to discharge or 30-day survival in adult patients receiving venoarterial $(V A)$ and venovenous $(W) E C M O$ in a quaternary care urban center. J Cardiothorac Vasc Anesth 33(4):910-917

10. Tanaka D, Hirose H, Cavarocchi N, Entwistle JWC (2016) The impact of vascular complications on survival of patients on Venoarterial extracorporeal membrane oxygenation. Ann Thorac Surg 101(5):1729-1734

11. Ferreira FL, Bota DP, Bross A, Melot C, Vincent JL (2001) Serial evaluation of the SOFA score to predict outcome in critically ill patients. JAMA 286(14): $1754-1758$

12. Laimoud M, Alanazi M (2020) The validity of SOFA score to predict mortality in adult patients with cardiogenic shock on venoarterial extracorporeal membrane oxygenation. Crit Care Res Pract 2020:3129864. https://doi.org/1 $0.1155 / 2020 / 3129864$

13. Lambden S, Laterre P, Levy M, Francois B (2019) The SOFA score-development, utility and challenges of accurate assessment in clinical trials. Crit Care 23:374

14. Kohler K, Valchanov K, Nias G, Vuylsteke A (2013) ECMO cannula review. Perfus (United Kingdom) 28(2):114-124

15. Green MS, Sehgal S, Tariq R (2016) Near-infrared spectroscopy: the new must have tool in the intensive care unit? Semin Cardiothorac Vasc Anesth 20(3):213-224

16. Moerman A, Wouters $P$ (2010) Near-infrared spectroscopy (NIRS) monitoring in contemporary anesthesia and critical care. Acta Anaesthesiol Belg 61(4):185-194

17. Lee DS, Chung CR, Jeon K, Park CM, Suh GY, Song Y (2016) Bin, et al. Survival after extracorporeal cardiopulmonary resuscitation on weekends in comparison with weekdays. Ann Thorac Surg 101(1):133-140

18. Yang F, Hou D, Wang J, Cui $Y$, Wang $X$, Xing $Z$ et al (2018) Vascular complications in adult postcardiotomy cardiogenic shock patients receiving venoarterial extracorporeal membrane oxygenation. Ann Intensive Care 8(1):72

19. Cheng R, Hachamovitch R, Kittleson M, Patel J, Arabia F, Moriguchi J et al (2014) Complications of extracorporeal membrane oxygenation for treatment of cardiogenic shock and cardiac arrest: a meta-analysis of 1,866 adult patients. Ann Thorac Surg 97(2):610-616

20. Pozzi M, Koffel C, Djaref C, Grinberg D, Fellahi JL, Hugon-Vallet E et al (2017) High rate of arterial complications in patients supported with extracorporeal life support for drug intoxication-induced refractory cardiogenic shock or cardiac arrest. J Thorac Dis 9(7):1988-1996

21. Gander JW, Fisher JC, Reichstein AR, Gross ER, Aspelund G, Middlesworth W et al (2010) Limb ischemia after common femoral artery cannulation for venoarterial extracorporeal membrane oxygenation: an unresolved problem. J Pediatr Surg 45:2136-2140

22. Kim J, Cho YH, Sung K, Park TK, Lee GY, Lee JM, Song YB, Hahn JY, Choi JH, Choi SH, Gwon HC, Yang JH (2019) Impact of cannula size on clinical outcomes in peripheral venoarterial extracorporeal membrane oxygenation. ASAIO J 65(6): 573-579 
23. Sandgren T, Sonesson B, Ahlgren R, Länne T (1999) The diameter of the common femoral artery in healthy human: influence of sex, age, and body size. J Vasc Surg 29(3):503-510

24. Lamb KM, DiMuzio PJ, Johnson A, Batista P, Moudgill N, McCullough M et al (2017) Arterial protocol including prophylactic distal perfusion catheter decreases limb ischemia complications in patients undergoing extracorporeal membrane oxygenation. J Vasc Surg 65(4):1074-1079

25. Johnson NJ, Acker M, Hsu CH, Desai N, Vallabhajosyula P, Lazar S et al (2014) Extracorporeal life support as rescue strategy for out-of-hospital and emergency department cardiac arrest. Resuscitation 85:1527-1532

26. Aziz F, Brehm CE, El-Banyosy A, Han DC, Atnip RG, Reed AB (2014) Arterial complications in patients undergoing extracorporeal membrane oxygenation via femoral cannulation. Ann Vasc Surg 28:178-183

27. Haneya A, Philipp A, Diez C, Schopka S, Bein T, Zimmermann M et al (2012) A 5-year experience with cardiopulmonary resuscitation using extracorporeal life support in non-postcardiotomy patients with cardiac arrest. Resuscitation 83:1331-1337

28. Kim SJ, Jung JS, Park JH, Park JS, Hong YS, Lee SW (2014) An optimal transition time to extracorporeal cardiopulmonary resuscitation for predicting good neurological outcome in patients with out-of-hospital cardiac arrest: a propensity-matched study. Crit Care 18:535

29. Swol J, Belohlavek J, Haft JW, Ichiba S, Lorusso R, Peek GJ (2016) Conditions and procedures for in-hospital extracorporeal life support (ECLS) in cardiopulmonary resuscitation (CPR) of adult patients. Perfusion 31:182-188

30. Conrad SA, Grier LR, Scott LK, Green R, Jordan M (2015) Percutaneous cannulation for extracorporeal membrane oxygenation by intensivists: a retrospective single-institution case series. Crit Care Med 43:1010-1015

31. Kalish J, Eslami M, Gillespie D, Schermerhorn M, Rybin D, Doros G et al (2015) Routine use of ultrasound guidance in femoral arterial access for peripheral vascular intervention decreases groin hematoma rates. J Vasc Surg 61(5):1231-1238

32. Laimoud M, Alanazi M (2020) Ultrasound-guided arterial catheterization in critical patients with nonpulsatile continuous circulation conditions on ventricular assist devices or veno-arterial extracorporeal membrane oxygenation support. Res Opin Anesth Intensive Care 7:308-312

33. Sobolev M, Slovut DP, Lee Chang A, Shiloh AL, Eisen LA (2015) Ultrasoundquided catheterization of the femoral artery: a systematic review and meta-analysis of randomized controlled trials. J Invasive Cardiol 27(7):318-323

34. Kashiura M, Sugiyama K, Tanabe T et al (2017) Effect of ultrasonography and fluoroscopic guidance on the incidence of complications of cannulation in extracorporeal cardiopulmonary resuscitation in out-of-hospital cardiac arrest: a retrospective observational study. BMC Anesthesiol 17:4. https:/doi.org/10.1186/ s12871-016-0293-z

35. Slottosch I, Liakopoulos O, Kuhn E, Deppe A-C, Scherner M, Madershahian N et al (2013) Outcomes after peripheral extracorporeal membrane oxygenation therapy for postcardiotomy cardiogenic shock: a single-center experience. J Surg Res 181(2):e47-e55

36. Danial P, Hajage D, Nguyen LS, Mastroianni C, Demondion P, Schmidt M et al (2018) Percutaneous versus surgical femoro-femoral veno-arterial ECMO: a propensity score matched study. Intensive Care Med 44(12):2153-2161

37. Madershahian N, Nagib R, Wipperman J et al (2006) A simple technique of distal limb perfusion during prolonged femoro-femoral cannulation. J Card Surg 21: $168-169$

38. Kasirajan V, Simmons I, King J et al (2002) Technique to prevent limb ischemia during peripheral cannulation for extracorporeal membrane oxygenation. Perfusion 17:427-428

39. Huang SC, Yu HY, Ko WJ et al (2004) Pressure criterion for placement of distal perfusion catheter to prevent limb ischemia during adult extracorporeal life support. J Thorac Cardiovas Surg 128:776-777

40. Schachner T, Bonaros N, Bonatti I et al (2008) Near infrared spectroscopy for controlling the quality of distal leg perfusion in remote access cardiopulmonary bypass. Eur J Cardiothorac Surg 34:1253-1254

41. Wong JK, Smith TN, Pitcher HT, Hirose H, Cavarocchi NC (2012) Cerebral and lower limb near-infrared spectroscopy in adults on extracorporeal membrane oxygenation. Artif Organs 36(8):659-667

\section{Publisher's Note}

Springer Nature remains neutral with regard to jurisdictional claims in published maps and institutional affiliations.

\section{Submit your manuscript to a SpringerOpen ${ }^{\circ}$ journal and benefit from:}

- Convenient online submission

- Rigorous peer review

- Open access: articles freely available online

High visibility within the field

- Retaining the copyright to your article

Submit your next manuscript at $\boldsymbol{\triangleright}$ springeropen.com 